\title{
O Processo de Cocriação de Valor nas Experiências de Consumo Colaborativo em Turismo: o caso Blablacar
}

\author{
Lucas Pereira Tomaz de Aquino \\ Maria de Lourdes de Azevedo Barbosab \\ José William de Queiroz Barbosac
}

\section{Resumo}

Este estudo buscou melhor compreender como ocorre a construção da cocriação de valor durante as experiências de turistas usuários das plataformas de consumo colaborativo, tendo como objeto de estudo o aplicativo de caronas BlaBlaCar. Para dar suporte teórico à pesquisa, foi realizado um levantamento bibliográfico sobre as experiências de consumo, a co-criação de valor e o consumo colaborativo. Para alcançar o objetivo proposto, a natureza qualitativa da pesquisa foi adotada, optando-se pela estratégia do estudo de caso. Para a coleta dos dados foram realizadas entrevistas semiestruturadas com usuários da mencionada plataforma, bem como foi elaborado um roteiro para observação do conteúdo do site como forma de realizar um contraponto entre os dados. Os resultados encontrados possibilitaram reconhecer a tendência a adoção de novos tipos de serviços colaborativos, bem como a mudança do comportamento dos consumidores. Obteve-se também uma melhor compreensão de como as experiências são desenvolvidas, identificando como ocorre a participação entre ofertantes e demandantes de serviços nesses novos formatos possibilitados por rede de computadores.

Palavras-chave: Turismo; Consumo colaborativo; Experiência de consumo; Cocriação.

\begin{abstract}
The Process of Co-creating Value in Experiences of Collaborative Consumption in Tourism: the Blablacar case

This study sought to better understand how the construction of value co-creation occurs during the experiences of tourists using collaborative consumption platforms, having as object of study the BlaBlaCar ride application. To provide theoretical support to the research, a bibliographic survey was conducted on consumption experiences, the co-creation of value and collaborative consumption. To achieve the proposed objective, the qualitative nature of the research was adopted, opting for the case study strategy. For data collection, semi-structured interviews were carried out with users of the aforementioned platform, as well as a script was developed to observe the content of the website as a way to carry out a counterpoint between the data. The results found made it possible to recognize the tendency to adopt new types of collaborative services, as well as to change consumer behavior. A better understanding of how the
\end{abstract}

a. Bacharelando em Hotelaria pela Universidade Federal de Pernambuco (UFPE). Recife, Pernambuco, Brasil. E-mail: lucas96.aquino@gmail.com

b. Doutora em Administração pela Universidade Federal de Pernambuco (UFPE). Docente do Programa de Pós Graduação em Hotelaria e Turismo na Universidade Federal de Pernambuco (UFPE). Recife, Pernambuco, Brasil. E-mail: lourdesbarbosa@gmail.com

c. Bacharel em Hotelaria pela Universidade Federal de Pernambuco (UFPE). Recife, Pernambuco, Brasil. E-mail: william.queirozb@hotmail.com 
experiences are developed was also obtained, identifying how participation between providers and demanders of services occurs in these new formats made possible by the computer network.

Keywords: Tourism; Collaborative consumption; Consumer experience; Co-creation.

\section{Resumen}

\section{El Proceso de Co-creación de Valor en Experiencias de Consumo Colaborativo en Turismo: el caso Blablacar}

Este estudio buscó comprender mejor cómo se produce la construcción de la cocreación de valor durante las experiencias de los turistas que utilizan plataformas de consumo colaborativo, teniendo como objeto de estudio la aplicación de viaje BlaBlaCar. Para proporcionar apoyo teórico a la investigación, se realizó una encuesta bibliográfica sobre experiencias de consumo, la co-creación de valor y el consumo colaborativo. Para lograr el objetivo propuesto, se adoptó la naturaleza cualitativa de la investigación, optando por la estrategia de estudio de caso. Para la recopilación de datos, se realizaron entrevistas semiestructuradas con los usuarios de la plataforma mencionada, y se desarrolló un guión para observar el contenido del sitio web como una forma de llevar a cabo un contrapunto entre los datos. Los resultados encontrados permitieron reconocer la tendencia a adoptar nuevos tipos de servicios de colaboración, así como a cambiar el comportamiento del consumidor. También se obtuvo una mejor comprensión de cómo se desarrollan las experiencias, identificando cómo se produce la participación entre proveedores y demandantes de servicios en estos nuevos formatos posibles gracias a la red informática.

Palabras clave: Turismo; Consumo colaborativo; Experiencia del consumidor; Co-creación

\section{INTRODUÇÃo}

0 advento e a massificação da internet ampliaram a possibilidade de conexão para a maioria das pessoas levando a uma perspectiva mais global das relações, o que significa que trabalhar em conjunto ganhou um sentido mais amplo e começou a se projetar em todas as esferas da sociedade, e por extensão, para as organizações e para as relações de consumo. Isso se reflete em uma nova estrutura econômica, denominada economia colaborativa.

Benkler (2006) afirma que no contexto contemporâneo a produção colaborativa emerge como sistema técnico social viável para motivar e organizar as contribuições coletivas humanas por meios que não são os contratos e a compensação monetária para uso de um dado capital físico. Essa transformação leva a um novo ambiente econômico, tecnológico e cultural que afeta diretamente as organizações e seus stakeholders, onde os consumidores assumem um papel importante na condução desse processo.

A existência e desenvolvimento do consumo colaborativo requerem que os indivíduos passem a gerar ações coletivas. Nesse contexto, a ação coletiva e a confiança são importantes facilitadores das práticas colaborativas (Bostman \& Rogers, 2011), que possibilitam um maior compartilhamento de informações (Dirks \& Ferrin, 2001) e são influenciadas pelo nível de identificação entre os indivíduos (Kramer, 1999).

As práticas colaborativas passaram a fazer parte das novas formas de consumo, tendo sua grande expansão no Brasil a partir da criação de alguns sites, 
como o Descola Aí (https://www.descolaai.com), em 2010, primeiro portal que permitiu o encontro de pessoas que buscavam alugar ou trocar seus objetos (Campi, 2011), o Peixe Urbano (https://www.peixeurbano.com.br/), também fundado em 2010, entre outros. A partir deles, outras plataformas vêm sendo criadas com diversas finalidades.

Esses serviços relacionais ou serviços colaborativos são o foco deste estudo, a partir da perspectiva dos seus participantes, tendo como objeto os serviços voltados à prática do turismo, na medida em que se fundamenta no que colocam Cipolla (2009) e Manzini (2003), ao explicarem que o termo "colaboração" surgiu a partir da percepção de que a qualidade das interações interpessoais estava muito distante de uma abordagem de entrega de serviço mais fluída.

0 exercício das práticas colaborativas impacta e modifica o comportamento do consumidor turista, afinal, diferentes indagações, percepções e valores emergem juntamente com elas. 0 que se pode perceber é que a participação ativa do turista nas relações de consumo parece ser cada vez maior, pois estes estão mais informados, interligados, ativos e com poderes de escolha (Prahalad \& Ramaswamy, 2004).

De acordo com Grönroos (2000) o valor é criado pelo consumidor a partir dos processos que participa, o que é reafirmado por Prahalad e Ramaswamy (2004), a partir do desenvolvimento da teoria de criação de valor, que diz que a co-criação entre organização e cliente surge como o centro da geração de valor. Vargo e Lusch (2016) vão ao encontro dessas ideias e assumem, a partir da perspectiva da Lógica Dominante do Serviço, que os consumidores passaram a ter um papel decisivo na co-criação de valor, considerando que estes são sempre co-criadores. Nesse contexto, a co-criação é eminentemente relacional e, por essa razão, é um elemento central no estudo do consumo colaborativo no contexto do turismo.

As relações de consumo emergentes em serviços designados, neste caso, como consumo colaborativo em turismo, apresentam uma perspectiva experiencial. Isso leva a reflexão de que os temas consumo colaborativo, co-criação e experiência se fundem na medida em que tem seu fundamento assentado na premissa de que quem define e interpreta sua experiência é o próprio indivíduo. 0 centro da experiência é a interação, pois, os indivíduos além de receberem estímulos de modo multissensorial, reagem a eles (Holbrook \& Hirschman, 1982).

Diante do contexto apresentado, o objetivo deste estudo é compreender o consumo colaborativo a partir da perspectiva das interações entre usuários da plataforma BlaBlaCar, sendo os serviços turísticos considerados como plataformas de co-criação de valor em que o nível de envolvimento dos consumidores pode variar em um continuum que pode ir desde uma participação mais passiva; para uma mais envolvente; até o engajamento, no qual há o comprometimento por parte de todos (Richards, 2014). Ou seja, buscou-se conhecer e avaliar de que modo ocorre o processo de co-criação de valor na construção de experiências de consumo colaborativo do turismo.

\section{EXPERIÊNCIAS DE CONSUMO EM TURISMO}

Dentre os autores que buscam uma melhor compreensão sobre as experiências de consumo de serviços turísticos, pode-se destacar Jensen (1999), que defende que as pessoas estão, cada vez mais, procurando satisfazer fatores emocionais, 
a partir do consumo de produtos e serviços que contem uma história e transformem suas viagens em algo emocionante e inesquecível.

Pine II e Gilmore (1999) defendem que o mundo passou pela era agrícola, industrial e de serviços, e chegou a era das sensações, o que chamam de "Economia da Experiência”. Segundo os autores, as pessoas anseiam por experiências sensoriais e aspectos ligados ao imaginário, cujas expectativas e percepções são individuais e de caráter subjetivo. As contribuições de Pine II e Gilmore (1999) foram significativas para o turismo, na medida em que o consumidor assume 0 protagonismo de suas viagens. Esses autores propuseram um modelo com quatro variáveis: entretenimento, aprendizagem, contemplação e evasão.

Este modelo apresenta os domínios da experiência, que são definidos em dois eixos: o horizontal, que apresenta o modo como o turista participa da experiência, havendo gradações num continuo que pode ir da participação mais ativa à participação mais passiva, e o vertical, onde tem-se em um extremo a "absorção", que representa a atenção mental das pessoas e no outro a "imersão" que é baseada na presença física do indivíduo durante a experiência. Essas dimensões devem ser consideradas quando se fala da importância da experiência memorável do turista e têm os seguintes significados:

a) contemplação: elementos que fazem o indivíduo decidir entrar em um local e permanecer ali;

b) evasão: capacidade de fazer com que o turista fique imerso nas atividades que lhe são propostas;

c) aprendizagem: é essencialmente ativa, e requer total participação do sujeito envolvido;

d)entretenimento: é um aspecto mais passivo da experiência, designa um estado de resposta aos elementos que lhe são apresentados.

De acordo com o que foi descrito, as experiências propostas pelos autores correspondem às várias experiências que as pessoas vivenciam no turismo. Dessa forma, esse modelo vem sendo aplicado como estratégia para planejamento de destinos turísticos (Horodyski, Manosso \& Gândara, 2014).

De acordo com Pereira, Siciliano e Rocha (2015, p. 09) a experiência de consumo é "o registro sensível, no indivíduo, da prática de consumir". As experiências de consumo, portanto, fornecem indícios para interpretar a lógica cultural, "[...] como via(s) de acesso ao imaginário do nosso tempo, em particular, a dimensão desse imaginário que se reflete na cultura de massa" (Rocha, 2006, p. 16) por estarem inseridas em um código, cujo significado é partilhado e público (Geertz, 1989; Pereira et al., 2015). As experiências de consumo "são exemplos de gatilhos que deslancham mais fortemente a habilidade de desejar, imaginar e experimentar emoções que caracterizam o consumo contemporâneo" (Pereira et al., 2015, p. 15).

Ao tratar da economia da experiência relacionada ao turismo, Tonini (2009, p. 104) a considera como "nada mais do que a tradução do consumo de signos, onde o elemento diferenciador, o exótico, o único, se transforma em emoções que traduzem símbolos sociais, distinções e fortalecem a importância do 'que tenho' perante 'quem sou', até porque 'quem sou' só é mostrado por meio do "que tenho". 


\subsection{Cocriação de valor nas relações de consumo do turismo}

A definição do que seja valor é dada pelo beneficiário de um produto ou serviço, o que pode gerar variações entre empresas e entre pessoas dentro da mesma organização (Lambert \& Enz, 2012). Ainda de acordo com os autores, a colaboração se inicia a partir do exame dos objetivos de cada uma das partes envolvidas, os quais devem convergir para que haja a cooperação.

De acordo com Payne, Storbacka e Frow (2008) são três os componentes principais da cocriação de valor:

- 1o componente: Processos de criação de valor do cliente - processos, recursos e práticas usados pelos clientes para desempenharem suas atividades;

- 2o componente: Processos de criação de valor dos ofertantes - processos, recursos e práticas usados pelos fornecedores para administrarem seu negócio e seus relacionamentos com os clientes e com outros stakeholders relevantes;

- 3o componente: Processos de encontro - processos e práticas da interação e do intercâmbio que ocorrem dentro do relacionamento cliente-ofertante, e que precisam ser administrados para o surgimento de oportunidades bem sucedidas de cocriação de valor.

Ao evidenciar a metáfora do que seria cocriação de valor, Grönroos (2012) diz que uma cocriação de valor inclui todos os elementos necessários para entender, planejar e responder às interações cliente-empresa de forma a dar suporte à criação de valor para ambos. Segundo o autor, a cocriação ocorre mediante o compartilhamento de recursos e a comunicação entre as partes. De acordo com Prahalad e Ramaswany (2004), a ideia de cocriação de valor envolve a interação entre consumidores e empresas com acesso bilateral de informações, em que a experiência individual de cada cliente, em determinado tempo e momento, resulta na geração e definição do valor que será agregado ao bem ou serviço.

Cova, Dalli e Zwick (2011) afirmam que o conceito de criação de valor carrega múltiplas interpretações: a concepção, o desenvolvimento e a produção de recursos devem ser entendidas como partes condicionantes da criação de valor, uma vez que ela mesma só pode ser considerada efetiva quando tiver seu resultado reconhecido pelo usuário do produto ou serviço. Para Grönroos e Voima (2013) os termos criação e cocriação de valor são distintos: a 'criação de valor' está relacionada ao valor em uso percebido pelo cliente; já a 'cocriação de valor' está associada à interação direta entre cliente e o fornecedor do produto ou serviço. Para esses autores a criação de valor é uma prerrogativa que parte do cliente, pois é ele quem determina o valor efetivamente gerado por um produto ou serviço. Dessa forma, a cocriação de valor só é possível quando há abertura do cliente à participação do fornecedor do serviço/produto, podendo interagir com o cliente, por meio de diálogo.

Troccoli (2009, p. 10) afirma que o recurso da Internet, ao assegurar a comunicação entre os clientes, tem feito surgir as "comunidades temáticas de clientes", onde os consumidores podem compartilhar ideias sem interferência de barreiras sociais/geográficas e sem depender das empresas servidoras do serviço. Nesse sentido, as plataformas de consumo colaborativo assumem papel de protagonistas, razão para a escolha de uma dentre elas como objeto de estudo desta pesquisa. 


\subsection{Consumo colaborativo no turismo}

A internet vem transformando a indústria do turismo ao longo das últimas duas décadas, pois os consumidores têm tido acesso mais fácil e rápido às informações (Kunz \& Seshadri, 2015). As comunidades online oferecem uma grande variedade de possibilidades para estabelecer, manter e desenvolver relacionamentos entre indivíduos e negócios. De acordo com Kunz e Seshadri (2015), os encontros online entre os viajantes frequentemente levam a relacionamentos offline. Em simultâneo, os serviços turísticos, que tradicionalmente eram ofertados somente por negócios como hotéis, táxis ou operadores turísticos se expandiram e ganharam novos formatos e vem sendo ofertados também por pessoas que se dispõem a compartilhar temporariamente o que possuem ou o que fazem. Desta maneira, práticas alternativas de negócios de turismo têm surgido a partir das novas tecnologias de redes sociais (Molz, 2013) e comunidades online, o que, provavelmente, ajuda usuários a construir relacionamentos offline (Kunz \& Seshadri, 2015).

Com a Internet e a Web 2.0, novas formas de compartilhamento foram criadas e formas antigas foram facilitadas (Belk, 2014). As práticas antigas de acesso a bens e serviços se desenvolveram de forma rápida e abrangente, envolvendo pessoas desconhecidas e distantes que puderam se interligar por meio das redes e plataformas digitais (Gansky, 2010). A partir dessas plataformas on-line, os indivíduos começaram a se conectar, compartilhar informações e cooperar entre si, realizando empréstimos, aluguéis, doações e trocas (Schor, 2015). Diante dessa realidade, o alcance a bens e serviços ficou mais fácil o que tem feito com que as pessoas percebam maior vantagem em ter o acesso às coisas do que ter a posse sobre elas (Gansky, 2010), desenvolvendo o que se chama de consumo colaborativo.

O consumo colaborativo é uma maneira de acomodar necessidades e desejos de uma forma mais sustentável, atraente e com menos ônus para o indivíduo (Botsman \& Rogers, 2011). Também chamado de economia mesh, o consumo colaborativo é considerado uma tendência que cresce a partir de novas organizações e novos modelos de negócio, com foco no compartilhamento (Gansky, 2010).

De acordo com Botsman e Rogers (2011), o consumo colaborativo compreende as práticas que possibilitam o acesso a produtos e serviços sem a necessidade de aquisição, ter a posse, ou até mesmo de pagar por eles, sendo uma maneira de suprir necessidades e desejos de forma mais sustentável, atraente e barata para o indivíduo. Para Ganksy (2010), o consumo colaborativo inclui a produção e distribuição compartilhada de bens e serviços por pessoas e organizações. Já para Lamberton e Rose (2012), os programas comerciais de compartilhamento traduzem as transações de compartilhamentos mediadas pelo mercado sem que haja a transferência de propriedade para o usuário. Em seu estudo sobre consumo colaborativo no turismo, Silva $(2018$, p. 31$)$ elaborou uma lista com algumas características em comum desse tipo de consumo:

a) É mediado pelas redes e plataformas on-line;

b) Possibilita a relação p2p entre os envolvidos (de pessoa para pessoa);

c) Pode ou não envolver intermediários entre as transações;

d) Pode ou não haver compensação financeira;

e) Possibilita o acesso a bens e serviços e não a propriedade. 
Apesar de oferecerem serviços e produtos variados e de se diferenciarem quanto sua essência, os diversos tipos de consumo colaborativo possuem quatro princípios em comum: a confiança entre desconhecidos, o poder da capacidade ociosa, a massa crítica e a crença no bem comum. Como este modelo de consumo exige transações entre pessoas que não se conhecem, é necessário haver confiança entre as partes que não se conhecem. A questão da capacidade ociosa diz respeito a aproveitar os produtos que não estão sendo utilizados para que outras pessoas possam usufruir, reforçando a ideia do acesso ao invés da posse. A massa crítica refere-se à disponibilidade suficiente dos produtos e serviços oferecidos de forma que as pessoas se sintam atraídas por eles e o sistema possa ser autossustentável. Por último, a ideia da crença no bem comum baseia-se na noção de que o compartilhamento pode trazer benefícios para todos, uma vez que, além do consumo, proporciona a colaboração (Botsman \& Rogers, 2011).

Ao relacionar o consumo colaborativo com o turismo, é possível ver que o impacto desse tipo de consumo no mercado turístico tem despertado atenção dos estudiosos em função da velocidade com que algumas plataformas estão crescendo, tendo como exemplo o Uber e o Airbnb. De forma parecida ao que acontece em outros mercados, acredita-se que essas plataformas colaborativas possam trazer benefícios para a atividade turística, pois proporcionam formas de consumo mais acessíveis e sustentáveis, além de contribuírem para aumentar o nível de autenticidade percebido nas experiências turísticas, a partir da relação direta estabelecida entre os participantes (Dredge \& Gyimóthy, 2015).

\section{PERCURSO METOdológico}

A procura por compreender um fenômeno complexo e de forma global, como é o caso deste objetivo de estudo, demandou a necessidade de utilização de métodos qualitativos (Neves, 1996). Por meio de um estudo de caso (Stake, 2006) foi possível conseguir insights sobre assuntos que dificilmente seriam obtidos por meio de pesquisas quantitativas (Aaker et al., 2001).

Tendo esta pesquisa uma abordagem subjetivista, admite-se que o conhecimento foi filtrado por meio dos pesquisadores e, desse modo, foi influenciado por forças cognitivas e culturais. A visão interpretativa aplicada ao estudo do comportamento do consumidor explicou com riqueza a situação em estudo e trouxe subsídios para a compreensão relativa do tema, não tendo a presunção de explicar todos os comportamentos de consumo, mas visando explorar e compreender os significados múltiplos atribuídos pelos indivíduos no contexto específico do consumo colaborativo em turismo, que por natureza é complexo. Nesse sentido, buscou-se o máximo da visão dos participantes sobre a situação estudada, extraindo os significados que estes atribuíram para o contexto do estudo (Creswell, 2010).

\subsection{Coleta de dados}

Para a obtenção dos dados, realizaram-se observações sistemáticas (Creswell, 2010) no Blablacar (https://www.blablacar.com.br), site escolhido 
como o caso deste estudo por ser a plataforma líder de caronas de longa distância no mundo. Uma comunidade que conecta quem procura uma viagem com quem tem espaço livre no seu carro. Com 60 milhões de membros em 22 países e 18 milhões de viajantes por trimestre, é uma rede inovadora de transporte. Tem equipe de suporte e plataforma (web e móvel) com tecnologia de ponta e a nossa crescente comunidade de confiança, o que faz da viagem via BlaBlaCar se constituir em uma experiência socialmente enriquecedora, financeiramente econômica e mais conveniente para os seus membros.

Foi realizada ainda uma pesquisa bibliográfica, além de informações constantes nos bancos de dados computadorizados como o Proquest, EBSCOHost, Journals e periódicos no Portal da CAPES, bem como outros Bancos de Dados Eletrônicos disponíveis na Biblioteca da Instituição de Ensino Superior (IES) e o site da empresa objeto deste estudo. Esses dados ajudaram a entender melhor o problema sob investigação e, em combinação com os dados primários, foram de grande valia para este estudo (Steward \& Kamins, 1993). Além desse aspecto, contribuíram com o exame da metodologia, ajudando também no planejamento da pesquisa, com a realização de comparações e para a sugestão de melhores métodos (Aaker et al., 2001). Também foram realizadas entrevistas semiestruturadas junto aos usuários do BlaBlaCar encontrados em comunidades inseridas em redes sociais, a partir de um roteiro semiestruturado (Manzini, 2003) com os consumidores que já tivessem vivenciado essa experiência de consumo colaborativo, visando obter informações sobre o problema de pesquisa, no período de julho de 2018.

\subsection{Seleção e caracterização da amostra}

Para selecionar a amostra, apenas um critério foi estabelecido: o respondente devia ter utilizado a plataforma BlaBlaCar pelo menos uma vez. A amostra final resultou em um total de 16 participantes. Foi divulgado um formulário elaborado no Google Forms, contendo alguns questionamentos, tais como: "Com qual frequência você usa o BlaBlaCar?"; "Como são as interações com o motorista durante a viagem?"; "Como essas interações com o motorista afetam a sua avaliação sobre o serviço utilizado?"; "Quais aspectos que o fazem lembrar da experiência com o BlaBlaCar?" etc.

No questionário, também haviam outras perguntas referentes a como o usuário conheceu a plataforma, motivações de uso, expectativas, tempo de uso, acessibilidade na plataforma, estrutura física do carro, maneira de dirigir do motorista, idade, gênero, escolaridade e renda. Estes questionamentos serviram para um melhor entendimento do perfil do usuário da plataforma e de como ocorrem as interações entre viajante e motorista.

Quanto à caracterização dos participantes, em relação a frequência de utilização da plataforma, a maioria da amostra afirmou que utiliza o BlaBlaCar pelo menos uma vez ao mês. Em relação há quanto tempo utilizam a plataforma, grande parte dos respondentes disseram que utilizam há pelo menos alguns meses. A maioria dos entrevistados estava entre a faixa etária de 19 a 26 anos. Quanto ao gênero, houve 8 respondentes mulheres e 8 respondentes homens. 


\subsection{Análise dos dados}

Os dados coletados a partir das entrevistas e observações foram transcritos, iniciando-se a fase de interpretação. Com os dados empíricos à disposição, praticou-se uma imersão relativa à experiência do consumo colaborativo buscando observar o fenômeno da forma como ele foi vivenciado, procurando uma empatia com os participantes das experiências. Em seguida se fez uma análise interpretativa dos dados, que se apoiou na revisão de literatura que deu suporte ao estudo, embora não tenha sido um processo de submissão total aos pressupostos teóricos.

Os dados coletados a partir das entrevistas e observações foram interpretados a partir da Análise Qualitativa Básica e, para tanto, foram criadas categorias analíticas (experiências com caronas, cocriação nos serviços de carona e colaboração entre usuários) para o exame mais acurado dos dados coletados, cujas atividades fundamentais incluíram a formulação de perguntas e a realização de comparações (Creswell, 2010). De acordo com o autor, "a investigação qualitativa emprega diferentes alegações de conhecimento, estratégias de investigação e métodos de coleta e análise de dados" (Creswell, 2010, p.184). Ao tratar sobre análise dos dados em investigações qualitativas, Creswell (2010, p.194) traz as seguintes colocações:

O processo de análise de dados consiste de extrair sentido dos dados de texto e imagem. Envolve preparar os dados para análise, conduzir análises diferentes, aprofundar-se cada vez mais no entendimento dos dados, fazer representação dos dados e fazer uma interpretação do significado mais amplo dos dados.

Além disso, foram adotados os passos genéricos de Creswell (2010) para análise de dados qualitativos, que consistem em: 1) organização e preparação dos dados; 2) leitura dos dados; 3) codificação dos dados; 4) descrição das categorias para análise; 5) transmissão dos resultados e 6) interpretação dos dados. Para isso, os dados foram tratados de forma computacional, a partir de planilhas específicas criadas pelos próprios autores, baseando-se nas orientações citadas de Creswell (2010) e nas categorias analíticas mencionadas anteriormente.

Para a efetivação das análises, além da transcrição das entrevistas, procurou-se realizar as suas leituras e releituras de maneira a confrontá-las entre si e com os dados coletados na observação da plataforma Blablacar. Assim, buscaram-se as semelhanças e as diferenças entre as informações, no intuito de enriquecer as análises, a partir das leituras e releituras tendo como elementos norteadores as categorias analíticas definidas. 0 Quadro 1 traz um panorama destas categorias e os construtos teóricos utilizados neste estudo. Em seguida, apresentam-se os resultados e discussões desta investigação.

Quadro 1 - Categorias analíticas e construtos teóricos

\begin{tabular}{|c|l|}
\hline Categorias Analíticas & Construtos Teóricos \\
\hline Experiências de consumo em turismo \\
\hline Experiências com caronas & $\begin{array}{l}\text { Autores: Jensen (1999); Pine II e Gilmore (1999); } \\
\text { Horodyski, Manosso \& Gândara (2014); Pereira, } \\
\text { Siciliano \& Rocha (2015); Tonini (2009). }\end{array}$ \\
\hline
\end{tabular}

(continua...) 
Quadro 1 - Continuação.

\begin{tabular}{|l|l|}
\hline \multicolumn{1}{|c|}{ Categorias Analíticas } & Construtos Teóricos \\
\hline $\begin{array}{l}\text { Cocriação nos } \\
\text { serviços de carona }\end{array}$ & $\begin{array}{l}\text { Cocriação de valor nas relações de consumo do turismo } \\
\text { Grönroos (2012); Prahalad e Ramaswany (2004). }\end{array}$ \\
\hline $\begin{array}{l}\text { Colaboração entre } \\
\text { usuários }\end{array}$ & Consumo colaborativo no turismo \\
\hline & $\begin{array}{l}\text { Autores: Kunz \& Seshadri (2015); Molz (2013); } \\
\text { Belk (2014); Gansky (2010). }\end{array}$ \\
\hline
\end{tabular}

Fonte - Elaboração própria (2020)

\section{RESULTADOS E DISCUSSÃO}

\subsection{Experiências de consumo em turismo: o caso BlaBlaCar}

Observou-se que o preço baixo do serviço BlaBlaCar tem um peso importante na escolha por sua utilização, o que vai de encontro aos elementos essenciais colocados no referido modelo, visto que este é um fator meramente utilitário, mas que influencia na opção pela experiência com esse serviço colaborativo, conforme alguns depoimentos a seguir:

O preço reduzido e curiosidade de como funcionavam as viagens compartilhadas (entrevistado 10).

Primeiro por querer viver a experiência da "carona", custo benefício e flexibilidade de horário de saída do ponto de partida, uma vez que os ônibus executivos não atendiam a minha necessidade por conta do horário de partida deles (entrevistado 12).

Gastar menos do que uma passagem de ônibus e chegar no destino escolhido mais rápido (entrevistado 13).

Além do preço, uma das falas acima revela o fator curiosidade para conhecer funcionamento das viagens compartilhadas, relevando a possibilidade de aprendizado e entretenimento (Pine II \& Gilmore, 1999) que surgem como elementos secundários ao preço.

Também foi possível notar que a interface da plataforma foi outro elemento abordado pelos entrevistados, revelando, assim, a importância deste item na decisão em usar o aplicativo:

Tem uma interface de fácil acesso (entrevistado 1).

Super acessível, bem tranquilo e fácil (entrevistado 8).

Boa, o app funciona relativamente bem, não apresentou nenhum problema técnico durante o uso, não travou, é de fácil acesso/uso e apresentou todas as informações necessárias para planejar a viagem (entrevistado 10). 
A forma positiva com que os entrevistados falaram sobre a interface da plataforma, demonstrou que este elemento serviu como facilitador do uso do aplicativo e fez com que os indivíduos provavelmente aderissem à plataforma, aspectos estes que demonstram relação com os aspectos evasão, aprendizagem e entretenimento integrantes do modelo de Pine II e Gilmore (1999).

Em relação à experiência da utilização do serviço, os itens que os respondentes mencionaram mais fortemente foram a qualidade do carro e a conformidade entre o que foi prometido e o que foi oferecido, reforçando que os elementos tangíveis surgiram como preponderantes nesse tipo de serviço colaborativo e que os aspectos mais contemplativos, de evasão, de aprendizagem e de entretenimento (Pine II \& Gilmore, 1999) foram deixados em segundo plano:

Afeta bastante, inclusive é um dos quesitos que mais levo em consideração. Acredito que é importantíssimo o motorista oferecer o carro conforme estava no anúncio. E sempre busco escolher carros novos e espaçosos (por conta da bagagem) e também visando conforto e segurança no decorrer da viagem (entrevistado 10).

O mínimo de conforto espera-se na hora da viagem. Eu, particularmente, me atento antes de fechar a carona, ao modelo do carro, prezando sempre por um conforto a mais é isso impactará também na minha avaliação, porém, quem tem o domínio, quase sempre é a necessidade do momento (entrevistado 12).

É necessário que o carro seja confortável, haja um espaço mínimo para pôr as pernas (banco de trás). Ar condicionado, odor agradável Todos esses quesitos são analisados (entrevistado 14).

Reforçando aspectos utilitários nas experiências de consumo no BlaBlaCar, outros elementos surgiram a partir dos depoimentos dos usuários foram os aspectos relacionados a pontualidade, a maneira responsável na condução do veículo e o respeito nas relações/interações entre motorista e passageiros e entre passageiros:

Horário pontual, valor da carona condizente, se comportamento dos motoristas cadastrados é respeitoso, infraestrutura do carro (entrevistado 1).

Boa condução, veículo seguro e confortável, interação e respeito entre os passageiros, pontualidade na saída e chegada e o preço acessivel (entrevistado 10).

Esses pontos levantados pelos respondentes demonstram um processo maior de interação e aprendizagem estabelecido entre usuários e prestadores dos serviços de carona, revelando que há um processo de aprendizagem conjunto que pode levar a uma experiência que pode levar a evasão e ao entretenimento (Pine II \& Gilmore, 1999).

O fator aprendizagem (Pine II \& Gilmore, 1999) foi um elemento reconhecido pelos usuários como importante para a experiência de consumo dos serviços do BlaBlaCar, principalmente via troca de informações entre usuários e motoristas e via avaliações dos serviços registradas na plataforma: 
Por ser um aplicativo de serviços e que visa o consumo colaborativo, em poder reduzir custos, compartilhar experiências de serviço/espaço, acredito que minha participação (usuário) deve ser o "norte" para manter o funcionamento estrutural e de dados entre os usuários e gestores do aplicativo (entrevistado 10).

Ao me submeter a utilizar o produto, em seguida utilizá-lo e avaliá-lo, contribuirei para as pesquisas de mercado da empresa, para seu crescimento financeiro e para seu desenvolvimento através de feedbacks (entrevistado 11).

Verifica-se, portanto, que comunicação e interação entre viajante e motorista é importante durante a experiência do serviço da BlaBlaCar, o que impacta nas avaliações feitas pelo usuário e pelo motorista após a carona finalizada. Essa participação mútua é determinante na reputação dos integrantes do serviço e no processo de colaboração e contribui para uma experiência de consumo positiva e marcante.

Outros aspectos apontados como integrantes da experiência com o BlaBlaCar foram o espírito aventureiro e o desconhecido, que de acordo com Pereira et al. (2015), seriam exemplos de gatilhos que deslancham a habilidade de desejar, imaginar e experimentar emoções que caracterizam o consumo contemporâneo:

Tenho lá meu espírito aventureiro, viajo com frequência, acredito na "boa ação" e intenção do próximo e concluo que bateu uma ansiedade quanto a viver a "carona" e sua dinâmica, uma ansiedade pra viver a experiência mesmo (entrevistado 12).

A princípio fiquei receoso de entrar no carro de um desconhecido, mas me senti seguro ao ler as avaliações dos passageiros antigos de outras caronas que o motorista já tinha oferecido (entrevistado 13).

Conforme as falas acima, foi possível identificar que alguns sentimentos afloraram nos usuários, tais como ansiedade em viver a experiência, tranquilidade e segurança. Sentimentos esses que se apresentaram também na interação entre motorista e o usuário da carona, sendo este um elemento importante para que a experiência com o serviço se caracterize tal como proposta no modelo de Pine e Gilmore (1999), sendo possível reconhecer aspectos de contemplação, evasão, aprendizagem e entretenimento:

Afetam bastante, acredito que o tratamento, conversa e interação durante a viagem é de extrema importância para as duas partes, tanto para quem oferece quanto para quem utiliza o serviço, ambos precisam sentir-se confortáveis para tudo ocorrer conforme o combinado e também voltarmos a utilizar o aplicativo (entrevistado 10).

O motorista acaba recebendo a carga de quase toda a expectativa de quem tá pegando a carona, acredito que ele assume o papel de protagonista e é peça fundamental para uma avaliação positiva no final do serviço, existem outros fatores que poderão interferir, claro (entrevistado 12).

Se o motorista for simpático, atencioso e, principalmente, educado, farei uma boa avaliação sobre ele (entrevistado 16). 
Pelo teor das respostas, foi possível observar que o consumidor do BlaBlaCar compreende a sua importância como indivíduo/consumidor durante todo o processo que envolve o uso da plataforma - seja no pré-consumo, momento da busca pela carona, no consumo, durante o uso do serviço de carona, onde ocorrem as interações com o motorista e/ou outros passageiros, e por fim, no pós-consumo, com a avaliação final de todo o processo de experiência da viagem.

\subsection{Cocriação de valor nas relações de consumo do turismo: o caso BlaBlaCar}

Buscando conhecer melhor o processo de co-criação de valor entre os usuários e os motoristas e demais passageiros do Blablacar, foram realizadas perguntas em relação à contribuição do passageiro para que a experiência da viagem fosse construída, tomado como base os autores Prahalad e Ramaswamy (2004) sobre a teoria da criação de valor, considerando-se que a co-criação entre a organização e o cliente nada mais é do que o centro da geração de valor para uma dada experiência.

As respostas sobre qual seria a contribuição dos usuários para a plataforma reforçaram a importância de se realizar a avaliação, manter o perfil atualizado na plataforma e cumprir, pelos envolvidos na experiência, os padrões de comportamento esperados e considerados como uma boa conduta social para se ter uma viagem pacífica:

Perfil no aplicativo atualizado, avaliações positivas, documentação enviada, foto recente no perfil (entrevistado 15).

Reservando a carona com a certeza de que será possível realizar a viagem, não desmarcando em cima da hora para que o motorista tenha a opção de preencher a vaga novamente, chegando ao local combinado de encontro com antecedência, etc (entrevistado 16).

Conforme os relatos acima, as contribuições podem fazer com que as interações entre cliente e motorista sejam interações positivas e agradáveis, gerando, assim, um valor cocriado entre os usuários e prestadores, a partir da qualidade das interações. Dessa forma, tem-se uma cocriação de valor.

A partir das observações das avaliações feitas na plataforma, pode-se verificar que tanto as informações constantes sobre o carro, o motorista, bem como as suas avaliações são elementos integrantes da experiência com o BlaBlaCar e, portanto, o serviço é co-criado nesse contexto.

Grande parte dos entrevistados demonstrou compreender a importância não só de avaliar o motorista, como também de manter o seu próprio perfil sempre bem avaliado e cumprir as exigências mínimas para que se possa manter a confiabilidade do aplicativo. De acordo com as respostas obtidas, houve um reforço do valor cultural que a utilização do BlaBlaCar pode trazer, em decorrência das interações com os motoristas, que ocorrem durante as viagens, e que são, em princípio, desconhecidos e com vivências diferentes, ocasionadas pela individualidade inerente de qualquer pessoa: 
A minha (e de qualquer pessoa) avaliação após o uso serviço, por exemplo, pode impactar tanto positivamente quanto negativamente para a continuação ou não do uso do aplicativo por parte de pessoas que não se sentem seguras em pegar uma carona ou que nunca tenham usado o serviço (entrevistado 12).

Como passageiro também estou sendo avaliado pelo motorista e outros motoristas irão ler as minhas avaliações no meu perfil antes de aceitar uma carona que eu solicite, então tento ser o mais pontual possível e ser uma companhia agradável durante a viagem (entrevistado 13).

Procuro sempre ser comunicativo, iniciar conversar e trocar experiências. A viagem acaba agregando um valor cultural e pessoal, pois acabamos conhecendo pessoas diferentes com histórias de vidas diferentes e muito interessantes (entrevistado 16).

Como visto acima, os usuários se preocupam em manter seu perfil sempre bem avaliado para que as interações sejam positivas. Isso é importante para manter a comunicação entre os usuários da plataforma, pois segundo Grönroos (2012), a cocriação ocorre mediante o compartilhamento de recursos e a comunicação aberta e direta entre as partes. Além disso, Grönroos e Voima (2013) dizem que a cocriação de valor está associada à interação direta entre cliente (nesse caso, o usuário da plataforma) e o fornecedor do produto ou serviço (nesse caso, o motorista do veículo).

\subsection{Consumo colaborativo no turismo: o caso BlaBlaCar}

Analisando a realidade da plataforma BlaBlaCar detectou-se que esta é uma plataforma online e que oferece possibilidades de desenvolver relacionamentos entre indivíduos e negócios, conforme afirmam Kunz e Seshadri (2015). Na plataforma, os relacionamentos se dão pelo contato do usuário com o motorista que oferece a carona no aplicativo. Dessa forma, pode-se dizer que a plataforma possibilita novas maneiras de criar vínculos entre as pessoas, mediada pela interação online.

Molz (2013) destaca que, tradicionalmente, os serviços turísticos só eram ofertados por negócios como hotéis, táxis ou operadores turísticos. Com a plataforma BlaBlaCar, verificou-se a possibilidade de novos e diferenciados serviços. Neste caso, o serviço turístico oferecido é a carona, onde o viajante pode optar por uma alternativa além do convencional táxi/ônibus/aluguel de carro, o que torna o transporte mais barato. Esta questão da economia vai ao encontro do que afirmam Botsman e Rogers (2011), quando dizem que o consumo colaborativo é uma maneira do indivíduo suprir suas necessidades de forma mais sustentável, atraente e barata. Além disso, também se encaixa como sendo um serviço de consumo colaborativo, uma vez que é ofertado por pessoas que se dispõem a compartilhar temporariamente o que possuem ou fazem (Molz, 2013). No caso da plataforma, os motoristas oferecem o que têm, ou seja, seus carros, por um determinado tempo, para dar caronas aos usuários do aplicativo em troca de determinada quantia.

Gansky (2010) afirma que as práticas antigas de acesso a serviços se desenvolveram e começaram a envolver pessoas desconhecidas que puderam se interligar por meio das redes e plataformas digitais. Isto está muito claro na plataforma 
BlaBlaCar, uma vez que o aplicativo permite que pessoas que não se conhecem possam interagir por meio da carona e, dessa forma, passar a se conhecer melhor enquanto o serviço está sendo prestado. É uma plataforma digital que possibilita a interação entre usuário (viajante) e prestador do serviço (motorista), ambos compartilhando experiências durante a carona oferecida.

Schor (2015) diz que a partir de plataformas online, os indivíduos começaram a se conectar, compartilhar informações e cooperar entre si, realizando empréstimos, aluguéis, doações e trocas. 0 que se vê na plataforma BlaBlaCar é que muitas pessoas utilizam este aplicativo, além de compartilhar suas informações pessoais em seu perfil e, quanto à cooperação, esta se dá pelo benefício que ambos recebem ao participar da carona que é oferecida pela plataforma: de um lado, o motorista se beneficia por ganhar um dinheiro extra ao fornecer seu carro e seu tempo para transportar viajantes e, do outro, o usuário adquire benefícios ao economizar em suas viagens que acontecem pelo aplicativo, uma vez que são mais baratas do que viajar em táxi convencional ou outro meio de transporte. Assim sendo, é possível afirmar que o alcance a bens e serviços ficou mais fácil pela tecnologia. Isso tem feito com que as pessoas percebam maior vantagem em ter acesso às coisas do que ter a posse sobre elas (Gansky, 2010), desenvolvendo o que se chama de consumo colaborativo.

\section{Conclusão}

A ascensão do consumo colaborativo, viabilizado pela tecnologia, aponta um tipo de turista com motivações e desejos um pouco diferentes do modo como o turismo tem sido experienciado nas últimas décadas. 0 BlaBlaCar é uma plataforma que oferece caronas para os seus usuários e que pode causar impactos sociais na medida em que o seu uso pode aproximar mais as pessoas e melhorar suas relações de confiança. 0 turista usuário do BlaBlaCar valoriza não só o baixo preço durante o transporte das viagens, mas também as interações e a socialização com o motorista durante o transporte até o local desejado.

Todo o processo de co-criação de valor é construído antes, durante e depois da viagem, cumprindo todo o processo da experiência de consumo do serviço. A interação entre o passageiro e o motorista é um elemento fundamental e as informações e avaliações constantes no site possibilitam a confiança mútua e a prática colaborativa. Sendo assim, acredita-se ter alcançado o objetivo central deste estudo: conhecer e avaliar de que modo ocorre o processo de co-criação de valor na construção de experiências de consumo colaborativo no turismo. A co-criação de valor na plataforma BlaBlaCar se dá em 06 etapas: busca da carona na plataforma; encontro do perfil do motorista; início da viagem; interações durante a viagem; finalização da viagem; avaliações do motorista e do passageiro.

0 consumo colaborativo é um modelo diferente do tradicional de consumir, viabilizado pela tecnologia e que permitiu mudanças ao mercado turístico pela forma como o turista assume o controle da sua experiência de viagem. Entender o consumo colaborativo e como ocorre a construção da cocriação de valor em suas plataformas irá permitir a organizações entenderem melhor as instabilidades do ambiente externo em constante mudança por conta da tecnologia, além de fornecer bases importantes para entender novas 
motivações dos consumidores em querer estar presente durante todos os processos de diferentes serviços.

Apesar do consumo colaborativo ser uma tendência na sociedade atual, cujas relações são beneficiadas pela rede, é possível elencar alguns impactos negativos na economia em relação aos trabalhadores formais que acabam "competindo" com este novo modo de consumir. Por exemplo, quando se fala em colaboração de caronas, o motorista profissional, contratado por uma empresa de transportes, pode perder espaço ou ter seu trabalho prejudicado pelos usuários de plataformas como a discutida nesta pesquisa, uma vez que, neste mercado de consumo colaborativo, não é necessário pagar impostos, nem fazer contratações, tampouco criar relações de trabalho. Os usuários destas plataformas colaborativas trabalham de forma autônoma, como uma alternativa ao modo de emprego tradicional. Dessa forma, acredita-se que esse tipo de consumo acaba substituindo o transporte coletivo, gerando maior desemprego para os motoristas que exercem esta atividade como profissão.

Como limitações desta pesquisa, pode-se mencionar que apenas uma plataforma foi analisada. Apesar dos achados deste estudo serem satisfatórios e de oferecerem contribuição para as lacunas existentes quanto ao que foi discutido aqui, acredita-se que com a análise de mais plataformas que se encaixem no que seja consumo colaborativo irá possibilitar comparações e achados mais profundos, além de contribuir para uma amostra maior de estudo. Portanto, como sugestão para pesquisas futuras, indica-se um estudo quantitativo, a fim de gerar resultados possíveis de generalização.

\section{REFERÊNCIAS}

Aaker, et al. (2001). Marketing Research (7a ed.), New York: John Wiley \& Sons, Inc.

Belk, R. (2014). You are what you can access: Sharing and collaborative consumption on-line. Journal of Business Research, 67, 1595-1600.

Benkler, Y. (2006). Commons-based peer production and virtue. The Journal of Political Philosophy, 4, 394-419.

Bostman, R., \& Rogers, R. (2011). O que é meu é seu: como o consumo colaborativo vai mudar o nosso mundo. Porto Alegre: Bookman.

Campi, M. (2011). Consumo colaborativo é o novo escambo 2.0. Info Online Abril. Referenciado de: <http://info.abril.com.br/noticias/tecnologias-verdes/consumo-colaborativo-eo-novo-escambo- 2.0-02062011-12.shl?p=3>. Acesso em: 13 abr. 2019.

Cipolla, C. (2009). Relational Services: service design fortering sustainability and new welfare models. Proceedings of the 2nd international Symposium on Sustainable Design. Brazil Network on Sustainable Design, RBDS. São Paulo: Brasil.

Cova, B., Dalli, D., \& Zwick, D. (2011). Critical perspectives on consumers' role as 'producers': Broadening the debate on value co-creation in marketing processes. Marketing Theory, 11(3), 231-241.

Creswell, J. (2010). Projeto de pesquisa: métodos qualitativo, quantitativo e misto. (3a ed.). Porto Alegre: Artmed.

Dirks, K. T., \& Ferrin, D. L. (2001). The role of trust in organizational settings. Organization Science, 12, 450-467. 
Dredge, D., \& Gyimóthy, S. (2015). The collaborative Economy and Tourism: Critical perspectives, questionable claims and silenced voices. Tourism Recreation Research, 40.

Gansky, L. (2010). The mesh: Why the future of business is sharing. New York: Portfolio Penguin.

Geertz, C. (1989). A Interpretação das Culturas. Rio de Janeiro: LTC.

Grönroos, C. (2000) Service logic revisited: who creates value? And who co-creates? European Business Review, 20(4), 298-314.

(2012). Conceptualising value co-creation: a journey to the 1970s and back to the future. Journal of Marketing Management, 28, 1520-1534.

\& Voima, P. (2013). Critical service logic: making sense of value creation and co-creation. Journal of the Academy of Marketing Science, 41, 133-150.

Holbrook, M. B., \& Hirschman, E. C. (1982). The experiential aspects of consumption: consumer fantasies, feelings and fun. Journal of Consumer Research, 9(2).

Horodyski, G. S., Manosso, F. C., \& Gândara, J. M. G. (2014). A Pesquisa Narrativa na Investigação das Experiências Turísticas Relacionadas ao Consumo de Souvenirs: uma abordagem fenomenológica. Turismo em Análise, 25(1).

Jensen, R. (1999). The Dream Society: how the coming shift from information to imagination will transform your business. New York: McGraw - Hill.

Kramer, R. M. (1999). Trust and distrust in organizations: emerging perspectives, enduring questions. Annual Review Phycology, 50, 569-598.

Kunz, W., \& Seshadri, S. (2015). From Virtual Travelers to Real Friends: Relationshipbuilding Insights from an Online Travel Community. Journal of Business Research, 68, 1822-1828.

Lambert, D. M., \& Enz, M. G. (2012). Managing and measuring value co-creation in businessto-business relationships. Journal of Marketing Management, 28, 1588-1625.

Lamberton, C. P. L., \& Rose, R. L. (2012). When Is Ours Better Than Mine? A Framework for Understanding and Altering Participation in Commercial Sharing Systems. Journal of Marketing.

Manzini, E. J. (2003). Considerações sobre a elaboração de roteiro para entrevista semiestruturada. In: Marquezine, M. C., Almeida, M. A., \& Omote, S. (Orgs.). Colóquios sobre pesquisa em Educação Especial. Londrina: Eduel, 11-25.

Molz, J. G. (2013). Social Networking Technologies and The Moral Economy of Alternative Tourism: The Case of Couchsurfing.org. Annals of Tourism Research, 43, 210-230.

Neves, J. L. (1996). Pesquisa Qualitativa - características, usos e possibilidades. Caderno de Pesquisas em Administração, São Paulo, 1(3).

Payne, A. F., Storbacka, K., \& Frow, P. (2008) Managing the co-creation of value. Journal of the Academy Marketing Science, 36, 83-96.

Pereira, C. S., Siciliano, T., \& Rocha, E. (2015). “Consumo de experiência" e "experiência de consumo": uma discussão conceitual. Cotidiano e Experiência, 22(2).

Pine II, B. J., \& Gilmore, J. H. (1999). The Experience Economy: work is theatre \& every business a stage. Massachusetts: Harvard Business School Press.

Prahalad, C. K., \& Ramaswamy, V. (2004). Co-creation Experiences: the next practice in value creation. Journal of Interactive Marketing, 18(3), 5-14.

Richards, G. (2014). Creativity and tourism in the city, Current Issues in Tourism. Referenciado de: <http://dx.doi.org/10.1080/13683500.2013.783794> . Acesso em: 24 fev. 2019. 
Rocha, E. (2006). Coisas estranhas, coisas banais: notas para uma reflexão sobre o consumo. In: Rocha, E., Almeida, M., \& Eugenio, F. (orgs.). Comunicação, consumo e espaço urbano: novas sensibilidades nas culturas jovens. Rio de Janeiro: Mauad/PUC-Rio.

Schor, J. (2015). Collaborating and Connecting: The emergence of the sharing economy. In: Reisch, L., \& Thogersen, J. Handbook on research on sustainable consumption. Cheltenham, UK: Edward Elgar.

Silva, L. A. (2018). Discurso e identidade no consumo colaborativo de turismo: uma investigação sobre a plataforma de viagens Airbnb e seus usuários. 190 p. Dissertação - Universidade Federal de Pernambuco, Recife.

Stake, R. (2006). Multiple Case Study Analysis. New York: The Guilford Press.

Steward, D., \& Kamins, M. (1993). Secondary Research: Information Sources and Methods (2a ed.). London: Sage Publications, Inc.

Tonini, H. (2009). Economia da experiência: o consumo de emoções na Região Uva e Vinho. Revista Brasileira de Pesquisa em Turismo. 3(1), 90-107.

Troccoli, I. R. (2009). Co-Criação de Valor e Fidelização dos Clientes: Uma Visão Integrada. Revista Científica Internacional, 2(4).

Vargo, S. L., \& Lusch, R. F. (2016). Institutions and axioms: an extension and update of service-dominant logic. Journal of the Academy of Marketing Science, 44(1), 5-23.

Recebido em: $30 / 07 / 2020$

Aprovado em: 17/10/2020

\section{CONTRIBUIÇÕES}

Lucas Pereira Tomaz de Aquino: Definição do problema de pesquisa e objetivos, desenvolvimento da proposição teórica, realização da revisão bibliográfica e fundamentação teórica, escolha dos procedimentos metodológicos, coleta e análise de dados, elaboração de tabelas, gráficos e figuras e redação do manuscrito.

Maria de Lourdes de Azevedo Barbosa: Definição do problema de pesquisa e objetivos, desenvolvimento da proposição teórica, realização da revisão bibliográfica e fundamentação teórica, escolha dos procedimentos metodológicos, análise de dados, revisão crítica e redação do manuscrito.

José William de Queiroz Barbosa: Realização da revisão bibliográfica e fundamentação teórica, elaboração de tabelas, gráficos e figuras, redação e adequação do manuscrito às normas da RTA, formatação do texto, aprimoramento do conteúdo e responsável pelas correções sugeridas pela revista. 